\title{
A dimensão tática do Futsal na cobertura jornalística de uma mídia impressa de Santa Maria-RS (1990 - 1999)
}

The tactical dimension of Futsal in the news coverage of a print media in Santa Maria-RSBrazil (1990 - 1999)

La dimensión táctica del Fútbol Sala en la cobertura informativa de un medio impreso en Santa Maria-RS (1990 - 1999)

Otávio Baggiotto Bettega ${ }^{\mathrm{I}}$, Cesar Vieira Marques Filho ${ }^{\mathrm{II}}$, Luís Felipe Nogueira Silva ${ }^{\mathrm{III}}$, Silvan Menezes Dos Santos ${ }^{\mathrm{IV}}$

\begin{abstract}
Resumo
A pesquisa busca identificar os sentidos atribuídos à dimensão tática do Futsal na cobertura midiática do jornal "A Razão", da cidade de Santa Maria - Rio Grande do Sul - Brasil. Foi realizada pesquisa descritiva e exploratória, de análise de produto midiático, com abordagem qualitativa dos dados recolhidos nos arquivos impressos do jornal, de 1990 até 1999. Os resultados apontam o ganho de visibilidade tática do papel do goleiro no jogo a partir das modificações nas regras, da relação entre o individual e o coletivo, das estratégias na relação ataque e defesa e da metodologia de treino e desenvolvimento dos jogadores. As matérias trazem visibilidade à dimensão tática do jogo de Futsal, mas são apresentadas de forma superficial e fragmentada.
\end{abstract}

Palavras-chave: Esporte; Tática; Mídia

\begin{abstract}
The research seeks to identify the meanings attributed to the tactical dimension of Futsal in the media coverage of the newspaper "A Razão" in the city of Santa Maria - Rio Grande do Sul - Brazil. A descriptive and exploratory research was carried out, analyzing media product, with a qualitative approach to the data collected in the newspaper's printed files from 1990 to 1999 . The results point to the gain of tactical visibility of the goalkeeper's role in the game from the changes in the rules, the relationship between the individual and the collective, offensive and defensive relationship strategies and the players' training and development methodology. The articles bring visibility to the tactical dimension of the Futsal game, but they are presented in a superficial and fragmented way.
\end{abstract}

Keywords: Sport; Tactic; Media

\footnotetext{
${ }^{\mathrm{I}}$ Universidade Estadual de Campinas - UNICAMP- e-mail: otavio.b.bettega@gmail.com - Endereço: Cidade Universitária Zeferino Vaz - Barão Geraldo, Campinas - SP, Brasil, CEP: 13083-970.

II Universidade Estadual de Campinas - UNICAMP - e-mail: cesarvmf@hotmail.com

${ }^{\mathrm{III}}$ Universidade Estadual de Campinas - UNICAMP - e-mail: luisfelipenogu@gmail.com
} 


\section{Resumen}

La investigación busca identificar los significados atribuidos a la dimensión táctica del Fútbol Sala en la cobertura mediática del periódico "A Razão" en la ciudad de Santa Maria - Rio Grande do Sul - Brasil. Se realizó una investigación descriptiva y exploratoria, analizando el producto de los medios, con un enfoque cualitativo de los datos recopilados en los archivos impresos del periódico desde 1990 hasta 1999. Los resultados muestran la visibilidad de la táctica del papel del portero en el juego a partir de los cambios en las reglas, la relación entre el individual y el colectivo, de las estrategias en la relación ataque y defensa y la metodología de entrenamiento y desarrollo de los jugadores. Los artículos aportan visibilidad a la dimensión táctica del juego de Fútbol Sala, pero se presentan de manera superficial y fragmentada.

Palabras clave: Deporte; Táctica; Medios de comunicación

\section{Introdução}

Nas discussões do contexto de origem do Futsal, duas vertentes são comumente evocadas: uma ligada ao cenário histórico uruguaio da década de 1930, e outra, ao brasileiro, entre as décadas de 1930 e 1940 (ANDRADE JÚNIOR, 1999). Ambas têm base na Associação Cristã de Moços (ACM), instituição que exerceu papel semelhante em outras modalidades (VOSER, 2003). Na trajetória do Futsal até os dias atuais, diversas mudanças foram realizadas nas regras, as quais alteraram, como consequência, as dinâmicas do jogo, ao impactar, tanto a dimensão tática, quanto as condições de preparação e competição das equipes.

A compreensão sobre as modificações das regras e as alterações provocadas na dinâmica do jogo esportivo carece de ampliações e novas articulações, que possam abarcar condicionantes sociais, culturais, econômicos, políticos, históricos e midiáticos que afetam o desenvolvimento da modalidade (HENRIKSEN; STAMBULOVA; ROESSLER, 2010). Nessa perspectiva, Marques e Marchi Júnior (2019) ressaltam que o pouco prestígio e visibilidade do Futsal, no subcampo midiático-esportivo, dificultam a atração de investimentos e o desenvolvimento de carreiras profissionais.

A simbiose da mídia com o esporte, além de influenciar dimensões econômicas e profissionais das modalidades esportivas (SPÀ, 1999), contribui, também, para a mediação da cultura esportiva contemporânea. A partir da construção e veiculação de discursos, o meio midiático-esportivo influencia os modos de ser e estar em relação ao esporte, bem como instiga diferentes formas de compreensão dos símbolos, códigos e valores (PIRES, 2002). Não é diferente com a modalidade Futsal, considerando as dinâmicas internas do jogo e os aspectos externos do contexto.

Compreender o esporte, nesse caso, o Futsal, passa impreterivelmente, por reconhecer sua dimensão tática. A tática configura-se como gestão intelectual do comportamento, a partir das diversas manifestações que emergem do jogo (GARGANTA, 2005). Ela estabelece relação com a estratégia, que se configura $a$ 
priori e com a técnica, que representa, em movimento, as intenções táticas (GALATTI et al., 2017). Tais relações entre estratégia, tática e técnica são seguidamente rompidas, no qual muitas análises isolam os componentes e comprometem o entendimento do jogo de Futsal sob uma perspectiva complexa (ANDRADE JÚNIOR, 1999; VOSER, 2003).

A dinâmica do jogo emerge de sua lógica interna, estabelecendo relações de cooperação e oposição em um contexto de imprevisibilidade e aleatoriedade, assim, gerando constantes modificações em sua configuração (SANTANA, 2004). Esse panorama apresenta grande subjetividade para as questões táticas do Futsal, que podem ser interpretadas a partir de diferentes pontos de vista. Nesse sentido, é interessante atentar aos aspectos relacionais entre as modificações das regras e a dinâmica do jogo, as posições e as funções estabelecidas, as ações individuais e coletivas, o comportamento do ataque e da defesa e o desenvolvimento dos ambientes de treino e competição (BETTEGA et al., 2015).

Dada a relevância histórica do período de transição entre as décadas de 1980 e 1990 para o Futsal, parte-se da perspectiva de mediação cultural da mídia esportiva, naquele contexto e época, sintomática aos modos de apresentação e compreensão da modalidade. Salienta-se que, nesse período, na década de 1990, o Futsal da cidade de Santa Maria obtinha um campeonato em nível municipal, bastante disputado, e também contava com equipes da cidade e da região, participantes das diferentes divisões (série ouro, prata e bronze) do campeonato estadual de Futsal. Destaca-se que, no ano de 1997, a equipe do "Jobi" de Santa Maria conseguiu o importante resultado de estar entre as 8 melhores equipes da série ouro, vencendo a expressiva equipe da Associação Carlos Barbosa de Futsal (ACBF). Nesse contexto, ressaltamos que um qualificado entendimento do jogo esportivo passa por um olhar à sua complexidade (GARGANTA, 2001). Sob tais lentes, desenvolvemos o estudo com o objetivo de identificar os sentidos atribuídos à dimensão tática da modalidade esportiva Futsal pela cobertura midiática do jornal A Razão, da cidade de Santa Maria - Rio Grande do Sul, durante a década de 1990.

\section{As mudanças nas regras que condicionaram a dimensão tática do jogo de Futsal}

A transposição do Futebol de Salão para o Futsal no final da década de 1980 e início da década de 1990 trouxe uma série de alterações nas regras do jogo. Essas modificações tinham como objetivo proporcionar maior dinâmica ao jogo, condicionando previamente aspectos ligados à dimensão estratégica e à tática do jogo. As primeiras mudanças nas regras estiveram relacionadas ao peso da bola, às dimensões no tamanho de quadra e, até mesmo, aos uniformes utilizados pela arbitragem. A área de meta foi aumentada, os assistentes de arbitragem foram banidos, o goleiro passou a jogar com os pés, o gol pôde ser marcado de dentro da área, o lateral passou a ser cobrado com os pés ao invés das mãos, as substituições 
(antes limitadas a cinco) foram aumentadas e, posteriormente, ilimitadas, e, também, surgiu o tiro livre após a quinta falta coletiva (ANDRADE JÚNIOR, 1999). Tais alterações nas regras levaram equipes a buscarem novas estratégias e, consequentemente, condicionaram a dimensão tática do jogo.

\section{Procedimentos Metodológicos}

A pesquisa se caracterizou como um estudo descritivo e exploratório (MARQUES et al., 2017), de análise de produto midiático (PIRES; LAZZAROTTI FILHO; LISBOA, 2012), com abordagem qualitativa dos dados. Assim se define o estudo, pois se descreve a compreensão tática do Futsal na mídia santamariense e apresentam-se reflexões analíticas, no sentido de aprofundar discussões e levantar novas questões de investigação sobre o tema. Ademais, ao observar e analisar, qualitativamente, o produto jornalístico de uma mídia local, procura-se trazer à tona uma forma de expressão sociocultural da modalidade esportiva Futsal, num dado contexto histórico, em especial a partir da visão de mundo de um meio de comunicação de massa específico.

Compuseram o estudo, notícias da editoria de esportes do Jornal A Razão, da década de 1990, que faziam menção ao Futsal de Santa Maria e da região. A escolha do formato de jornal impresso se deu, justamente, por se tratar de um período relevante e transitório para o Futsal, mas que antecede a convergência digital dos meios de comunicação de massa. As notícias foram recolhidas no Arquivo Municipal de Santa Maria, no qual disponibilizou o espaço para a investigação e todo o material para a coleta. No desenvolvimento da pesquisa, algumas das edições do jornal não estavam disponíveis no acervo (mês de fevereiro de 1994 e meses de maio, junho, julho e agosto de 1997).

Por não existir um arquivo digitalizado do período estabelecido para a investigação, foi necessário, considerando a extensão do material de consulta, fotografar todas as notícias relacionadas ao objeto de estudo. No montante dos 10 anos recorridos, 1018 fotos foram tiradas. A seleção das notícias foi feita através da leitura e análise do texto, buscando, no conteúdo, relatos que fizessem referências à dimensão tática do jogo de Futsal como importante atributo à compreensão do jogo. A partir desse processo, foram selecionadas 10 matérias jornalísticas, integrantes do substrato do processo descritivo-analítico.

As matérias foram escolhidas a partir de uma ideia central de tática, que preconiza a gestão intelectual do comportamento a partir das diversas manifestações emergentes do jogo (GARGANTA, 2005) e que se inter-relaciona com os aspectos técnicos e estratégicos (GALATTI et al., 2017). Nessa perspectiva, compreendemos que as matérias selecionadas e posteriormente categorizadas apresentam relação com os desdobramentos táticos provenientes do jogo. Após, um roteiro de indagações originou uma nova lente para 
a análise criteriosa do texto e consequente seleção do conteúdo (SCHMITZ FILHO, 2005). As notícias foram organizadas e interpretadas por meio de análise de conteúdo, de modo que, através da identificação de unidades de registro do entendimento tático apresentado pela mídia analisada, elaboramos cinco categorias analíticas apresentadas e discutidas na sequência do texto.

\section{Resultados e Discussão}

Os resultados da pesquisa, durante um recorte de dez anos, trazem matérias jornalísticas relacionadas com a dimensão tática do jogo, mas, por vezes, expostas de maneira superficial, dificultando melhor compreensão. Essa exposição evidencia a importância da veiculação da dimensão tática, sob a égide da complexidade, nos discursos midiático-esportivos. Nesse sentido, são apontadas aqui, cinco categorias de análise:

- Modificações nas regras.

- O papel do goleiro no jogo.

- Relação entre o individual e o coletivo.

- Estratégias na relação entre ataque e defesa.

- Metodologia de Treino e Desenvolvimento dos jogadores.

A dimensão tática representa a essência do jogo e fundamenta relações estabelecidas entre os jogadores e as equipes. Logo, ganha relevância o seu desenvolvimento em contextos de treino e competição. Como apresentado a seguir, foi reportado a um jornal impresso para identificar como ela recebe visibilidade na mídia.

\section{Modificações nas regras}

O período entre o final da década de 1980 e início da década de 1990 marca a alteração do nome da modalidade, que deixa de ser chamada Futebol de Salão para ser conhecida como Futsal. Nesse período, foi realizada uma série de alterações nas regras do jogo, visando configurar uma alternativa menos violenta, mais dinâmica e atrativa (SALLES; MATTOS, 1996). A Figura 1 traz duas notícias das modificações nas regras e dos desdobramentos sobre as dimensões estratégica e tática do jogo. 
Figura 1 - Notícias sobre as modificações nas regras

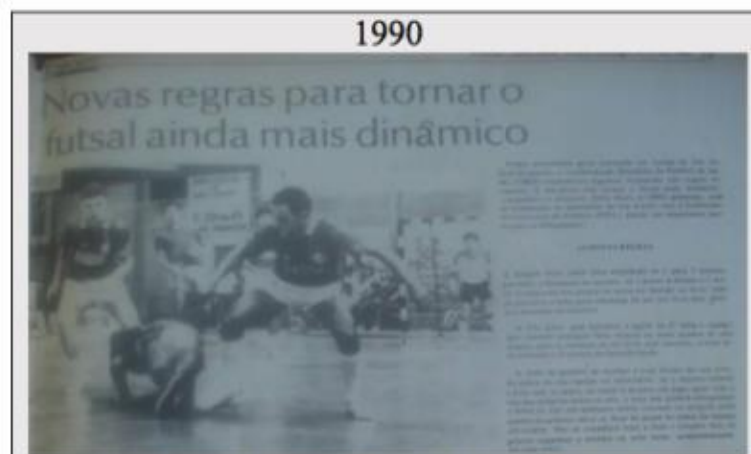

\section{NOVAS REGRAS PARA TORNAR O FUTSAL} AINDA MAIS DINÂMICO

"Numa assembleia geral realizada em Caxias do Sul no final de janeiro, a Confederação Brasileira de Futebol de Salão (CBFS) estabeleceu algumas mudanças nas regras do esporte. A iniciativa visa tornar o Futsal mais dinâmico, competitivo e atraente. Além disso, a CBFS pretende com as mudanças, se aproximar de um acordo com a Federação Internacional de Futebol (FIFA), dando um importante passo para as Olimpiadas".

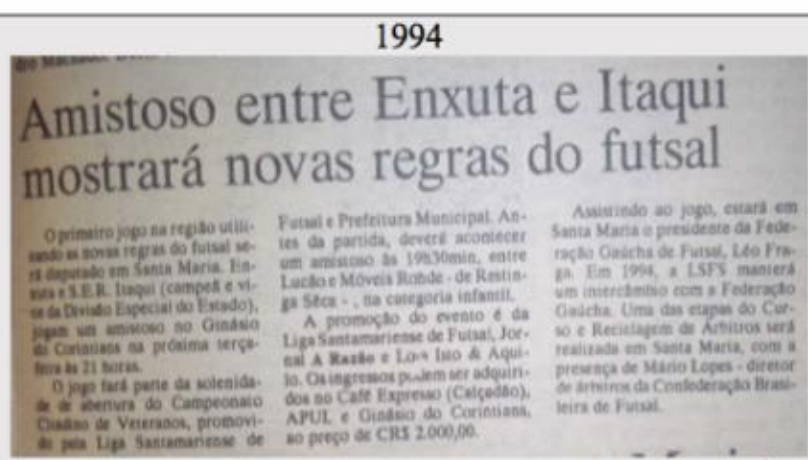

AMISTOSO ENTRE ENXUTA E ITAQUI MOSTRARÁ NOVAS REGRAS DO FUTSAL

"O primeiro jogo na região utilizando as novas regras do Futsal será disputado em Santa Maria. Enxuta e S.E.R. Itaqui (campeã e vice da Divisão Especial do Estado), jogam um amistoso no Ginásio do Corinthians na próxima terça-feira às 21 horas".

Dentre as mudanças, a cobrança do lateral, efetuada com as mãos, passou a ser realizada com os pés. Essa alteração promoveu modificações nas jogadas, a partir dos arremessos laterais, ao dificultar o lançamento de bolas em espaços mais distantes e de forma mais precisa, bem como facilitou a recepção da bola com os pés em distâncias mais curtas, favorecendo aproximações e possibilidades para conservação da posse de bola. Os estudos de Duarte (2008) e Caetano e colaboradores (2015) indicam a importância da manutenção da posse de bola no Futsal, mas ressaltam que o desempenho nos jogos depende da criação de oportunidades de arremates ao gol e consequente eficácia nas ações de finalização.

A proibição do retorno do passe ao goleiro foi outra alteração que influenciou diretamente na manutenção de posse de bola e progressão ao alvo, dois dos princípios operacionais aludidos por Bayer (1994). A nova regra retirou a possibilidade de mais uma linha de passe (do goleiro) para organização do ataque no campo defensivo e dificultou a manutenção da posse, principalmente em momentos de pressão da equipe oponente. $\mathrm{O}$ gol passou a ser válido dentro da área de meta do adversário e exigiu que a defesa elaborasse marcações individuais mais próximas da sua baliza, enfatizando princípios táticos, como aproximação e abordagem e realização de coberturas (SAAD et al., 2014), pois as mudanças nas regras ampliaram os espaços para finalização perto da baliza. $O$ número de substituições foi novamente aumentado (de sete para dez), ampliando o leque de alternativas para modificar as características da equipe em momentos ofensivos e defensivos (KUMAHA et al., 2009). 
Nesse item, sobre modificações das regras, visualizam-se a amplitude e complexidade de interferência desse processo na mudança do jogo do Futsal. Em dissonância, destaca-se a simplificação de tal contexto por parte da mídia analisada, visto que, ao mencionar as transformações da modalidade esportiva, detém-se ao factual. Os constructos noticiosos mencionados anteriormente demonstram como o jornal, nessa situação, restringe-se a dois episódios ${ }^{1}$ daquela década, um referente à situação institucional da mudança das regras e outro de uma partida de exibição das novidades, ocorrida na região de circulação do jornal. Identifica-se tais dados como um primeiro indício da contribuição fragmentária da mídia na mediação informativa e cultural sobre o jogo esportivo coletivo em análise.

\section{O papel do goleiro no jogo}

As mudanças de regras no Futsal influenciaram de forma significativa a atuação do goleiro. As possibilidades de participação ativa deste jogador estabeleceram novas estratégias e combinações táticas. Na Figura 2, são abordadas duas notícias sobre a participação do goleiro, na matéria do ano de 1993, a troca de um goleiro por outro é isolada do aspecto tático, e, na matéria de 1997, é salientada a importância do goleiro nos momentos de defesa e ataque, mas sem maiores justificativas.

Figura 2 - Notícias sobre o papel do goleiro no jogo

\begin{tabular}{|c|c|}
\hline 1993 & 1997 \\
\hline SM/Raízes recebe Plátano no Farrezāo & $\begin{array}{l}\text { Colvero Orienta novas regras } \\
\text { Colve }\end{array}$ \\
\hline 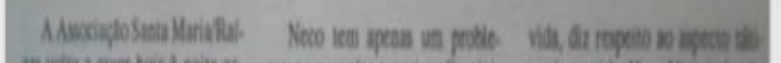 & 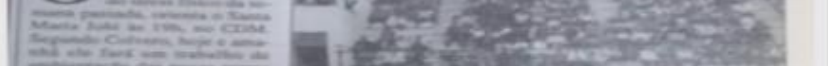 \\
\hline 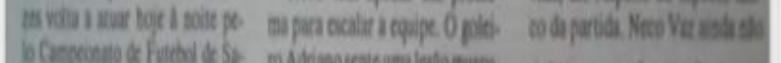 & 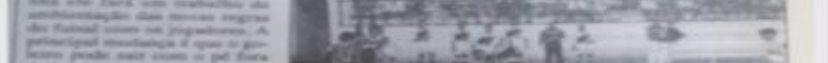 \\
\hline 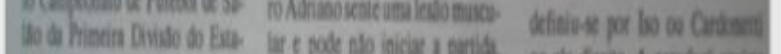 & 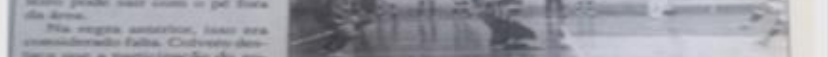 \\
\hline 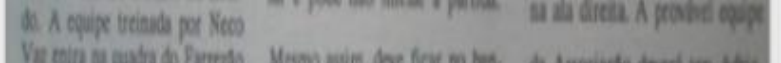 & $=\sqrt{2}=-2-15$ \\
\hline 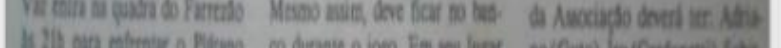 & $3=-1-150$ \\
\hline 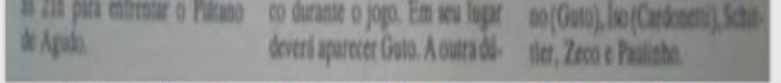 & 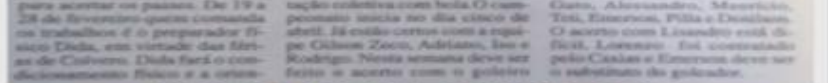 \\
\hline SM/RAIIZES RECEBE PLÁTANO NO FARREZÃO & COLVERO ORIENTA NOVAS REGRAS \\
\hline $\begin{array}{l}\text { "Neco tem apenas um problema para escalar a equipe. O } \\
\text { goleiro Adriano sente uma lesão muscular e pode não iniciar a } \\
\text { partida. Mesmo assim, deve ficar no banco durante o jogo. Em } \\
\text { seu lugar deverá aparecer Guto. A outra dúvida, diz respeito ao } \\
\text { aspecto tático da partida. Neco ainda não definiu-se por Izo ou } \\
\text { Cardonetti na ala direita". }\end{array}$ & $\begin{array}{l}\text { "Segundo Colvero, hoje e amanhã ele fará um trabalho de } \\
\text { ambientação das novas regras do futsal com os jogadores. A } \\
\text { principal mudança é que o goleiro pode sair com o pé fora da área. } \\
\text { Na regra anterior, isso era considerado falta. Colvero destaca que } \\
\text { a participação do goleiro torna-se muito importante, pois além de } \\
\text { defender ele terá que atacar. A nova regra exige que os goleiros } \\
\text { tenham habilidade também com os pés, para acertar os passes". }\end{array}$ \\
\hline
\end{tabular}

\footnotetext{
${ }^{1}$ Segundo Rothberg (2010, p. 56), enquadramentos midiáticos episódicos não selecionam e tampouco enfocam questões políticas e de maior complexidade do entorno do fato. Para o autor, eles "[...] apenas acentuam aspectos circunstanciais dos fatos enfocados". Por sua vez, os enquadramentos temáticos seriam a alternativa possível para superar o caráter fragmentário e superficial promovido pelos episódicos. Essa abordagem exige do jornalista a capacidade de situar o fenômeno em questão dentro do contexto mais amplo em que se insere.
} 
Dentre as mudanças ocorridas que influenciaram a participação do goleiro no Futsal, destaca-se a possibilidade de atuação fora da área de meta, por promover novas configurações táticas no jogo. Desse modo, Bueno e colaboradores (2018) indicam que as zonas de atuação do goleiro influenciam no número de finalizações no gol e interceptações. O goleiro, além do usual posto de defender as finalizações direcionadas à baliza e de realizar coberturas defensivas, aparece também na fase ofensiva, sustentando por vezes, a manutenção da posse de bola, e auxiliando em superioridade numérica para organização do ataque e criação de possibilidades de finalização.

Nos jogos das semifinais e final da Copa do Mundo de Futsal em 2008, os goleiros tiveram participação constante na manutenção da posse de bola, com passes realizados na quadra defensiva, principalmente ao longo da primeira etapa e início da segunda etapa do jogo (GANEF et al., 2009). Segundo os mesmos autores, a participação do goleiro, com a realização de passes na quadra ofensiva, ocorreu, especialmente, na porção final das partidas, e com as equipes em adversidade no placar. No estudo de Souza e colaboradores (2018), na Liga Nacional de Futsal 2016, foi realizada uma comparação entre as ações dos goleiros, propriamente ditos, e dos jogadores de linha na posição do goleiro (goleiro-linha). Os resultados mostraram que os goleiros tendem a auxiliar mais na fase ofensiva nos arremessos laterais, e como apoio em situações de pressão do adversário, enquanto os jogadores de linha na posição de goleiro possibilitam mais oportunidades de finalizações. Além disso, a utilização do goleiro tende a aumentar a efetividade nos momentos de manutenção de posse de bola e a diminuição da pressão da equipe adversária (VICENTEVILAS; LAGO-PEÑAS, 2016).

Nessa categoria analítica, sobre o papel dos goleiros no jogo, destaca-se a diferença de abordagem por parte da mídia em relação à categoria anterior. Mesmo que, na notícia de 1993, possa ser vista uma leitura que fragmenta e isola a atuação do goleiro no jogo, na notícia de 1997, tem-se indícios de um enquadramento midiático mais amplo sobre o tema, que expande a compreensão sobre as possibilidades e necessidades de participação desses jogadores. Nesse segundo caso, a mobilização do treinador Colvero, como fonte primária da construção da notícia, apresenta-se como principal indicativo para tal abordagem ampliada do fenômeno. Entretanto, ainda assim, a informação veiculada não detalha o quão complexo é o papel dos goleiros no jogo, como destacado na literatura supracitada. Vale ressaltar, que naquela ocasião (década de 1990), as novas funções e demandas de ação dos jogadores estavam em processo de compreensão por todos os interessados na modalidade, sejam treinadores e atletas, sejam gestores e jornalistas. 
Relação entre o individual e o coletivo

As notícias, em muitos momentos, atribuem o sucesso ou insucesso de algumas situações de jogo, exclusivamente, à atuação individual dos jogadores, descaracterizando relações entre o individual e o coletivo. Na Figura 3, a matéria de 1995 indica o time apático, com falhas de marcação e erros de passes, apontando a causa dos gols a partir de falhas individuais, sem relacioná-las à tática coletiva. A matéria de 1998 mostra a equipe visitante conseguindo boas triangulações e também ressalta que a eficácia da defesa adversária passa pela atuação individual do goleiro, assim, desconsiderando aspectos da organização defensiva coletiva.

Figura 3 - Notícias sobre a relação entre o individual e o coletivo.

\begin{tabular}{|c|c|}
\hline 1995 & 1998 \\
\hline SM/Raízes perde para o Inter/ULBRA & Jobi vence e sobe para $8^{a}$ posição \\
\hline 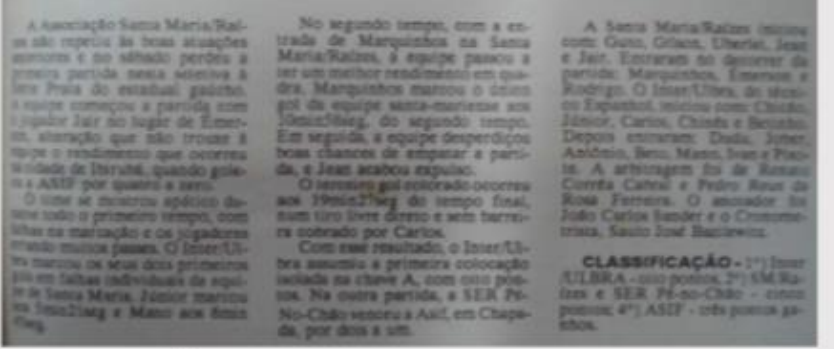 & 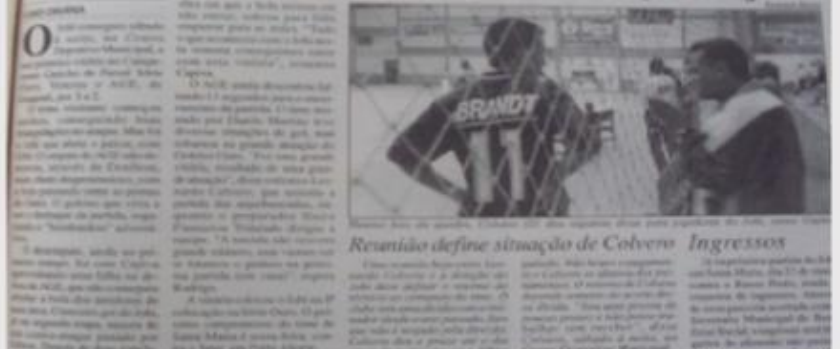 \\
\hline SM/RAIZZES PERDE PARA O INTER/ULBRA & $\underline{\text { JOBI VENCE E SOBE PARA A } 8^{\mathrm{a}} \text { POSIÇÃO }}$ \\
\hline $\begin{array}{l}\text { "O time se mostrou apático durante todo o primeiro tempo, } \\
\text { com falhas na marcação e os jogadores errando muitos } \\
\text { passes. O Inter/Ulbra marcou seus dois primeiros gols em } \\
\text { falhas individuais da equipe de Santa Maria. Júnior marcou } \\
\text { aos } 5 \text { min } 21 \text { seg e Mano aos } 8 \text { min } 45 \text { seg". }\end{array}$ & $\begin{array}{l}\text { "O time visitante começou melhor, conseguindo boas } \\
\text { triangulações no ataque. Mas foi o Jobi que abriu o placar, } \\
\text { com Jibi. O empate da AGE não demorou, através de } \\
\text { Denilson, num chute despretensioso, com a bola passando } \\
\text { entre as pernas de Guto. O goleiro que viria ser o destaque } \\
\text { da partida, segurando o bombardeio adversário". }\end{array}$ \\
\hline
\end{tabular}

Amaral e Garganta (2005) investigaram, tomando como base jogos da primeira divisão do Campeonato Português de Futsal ( $1^{\circ}$ divisão), situações de confrontos individuais, o “1x1”. Os resultados mostraram que as situações de "1x1", quando realizadas no campo ofensivo, tendem a aumentar a probabilidade de desequilíbrio sobre a defesa adversária, apresentando maior probabilidade de potencializar finalizações, em contexto de cooperação, com vários apoios. Travassos e colaboradores (2011) analisaram situações de jogo em que um atleta de linha ocupou a posição do goleiro, para buscar superioridade numérica. Os resultados mostram as posições designadas aos jogadores como influentes nas relações de fase das díades em jogo, em que defensores da esquerda e da direita desenvolveram um forte acoplamento 
em fase com o goleiro na direção lateral. Esse resultado é atribuído ao objetivo defensivo de manter compacta a organização em relação à bola e à área da meta defendida. Desse modo, é relevante que o comportamento dinâmico das equipes seja investigado, considerando os diferentes níveis de interação, do individual ao coletivo (GALATTI et al., 2017).

Ainda no início do século XXI, Betti (2001) descreve a atuação da mídia no contexto do esporte para além de informar e atualizar, ocorrendo por meio da constatação de histórias, "[...] das partidas, das lutas, das corridas, dos campeonatos; uma história sempre construída e reconstruída, pontuada pelos melhores momentos - os gols, as ultrapassagens, os acidentes etc". Além da centralização do foco midiático em pontos momentâneos do espetáculo em jogo, há décadas tem se identificado certa tendência do jornalismo esportivo de personificação na construção das notícias (HELAL, 1998; SANTOS; MEDEIROS, 2009). Nesse sentido, o modo de individualização das situações táticas do Futsal, observadas na cobertura jornalística do jornal A Razão, reiteram a lógica informativa da mídia esportiva. Como vimos, a mídia analisada centra-se em momentos pontuais e cruciais do jogo, personifica situações de sucesso e insucessos, rompendo, assim, a indissociabilidade da relação indivíduo e coletivo na configuração das modalidades esportivas coletivas.

Estratégias na relação entre ataque e defesa

O Futsal se caracteriza como uma modalidade de cooperação e oposição, logo, necessita ser compreendido com base nessas relações. A Figura 4 mostra duas matérias, uma de 1991, indicando que o treinador de uma das equipes tinha como objetivo organizar uma estratégia de jogo defensiva para neutralizar as jogadas de ataque do adversário. Outra matéria, de 1996, o noticiário ressalta que uma das equipes obteve dificuldade nas infiltrações e nas jogadas com a utilização do pivô, devido ao sistema defensivo do adversário, organizado a partir da metade da quadra. 
Figura 4 - Notícias sobre as estratégias na relação entre ataque e defesa

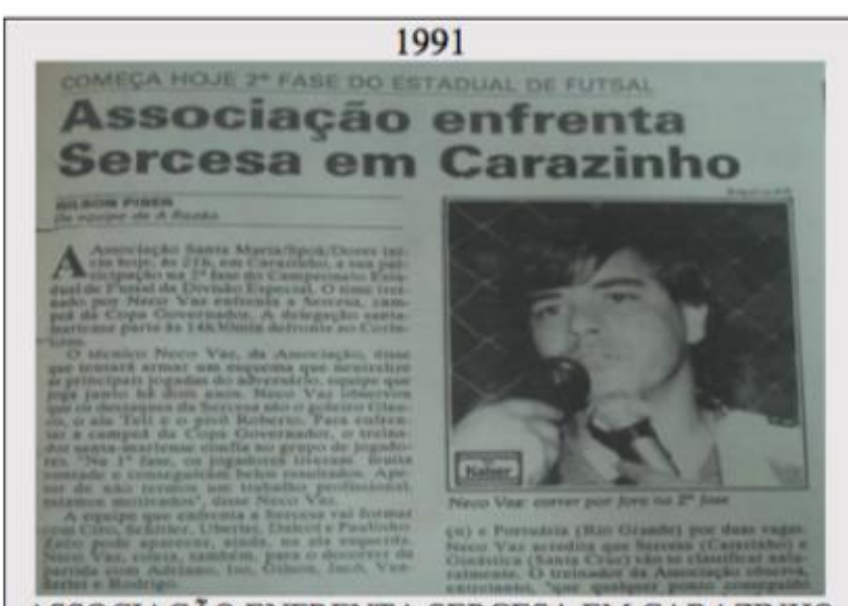

ASSOCIACূÃO ENFRENTA SERCESA EM CARAZINHO

"O técnico Neco Vaz, da Associação, disse que tentará armar um esquema que neutralize as principais jogadas do adversário, equipe que joga junto há dois anos. Neco Vaz observou que os destaques da Sercesa são o goleiro Glauco, o ala Téti e o pivô Roberto. Para enfrentar a campeã da Taça Governador, o treinador santa-mariense confia no grupo de jogadores".
1996

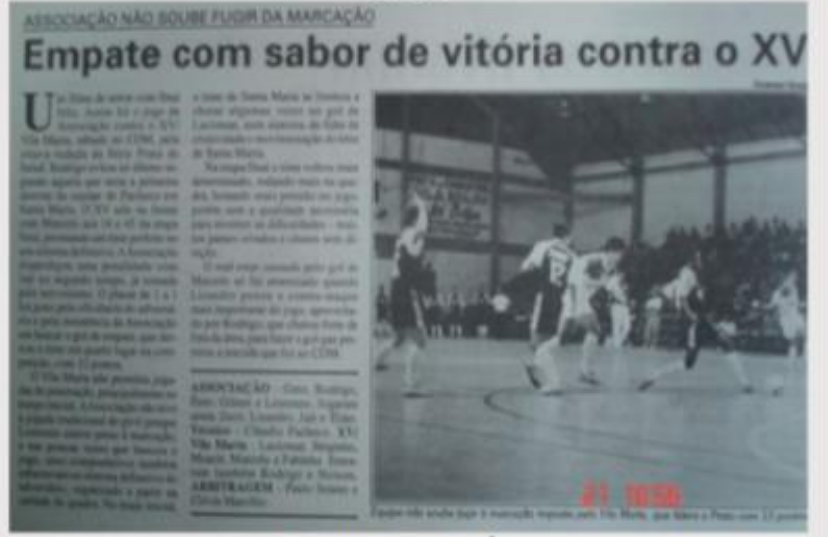

EMPATE COM SABOR DE VITÓRIA CONTRA O XV

"O Vila Maria não permitiu jogadas de penetração, principalmente no tempo inicial. $\mathrm{A}$ Associação não teve $\mathrm{a}$ jogada tradicional do pivô porque Lorenzo esteve preso à marcação, e nas poucas vezes que buscou o jogo, seus companheiros também esbarravam no sistema defensivo do adversário, organizado a partir da metade da quadra. Na etapa inicial, o time de Santa Maria se limitou a chutar algumas vezes no gol de Luciomar, num sintoma da falta de criatividade e movimentação do time de Santa Maria".

As estratégias de jogo estabelecidas em uma equipe devem considerar suas características e não se ater, apenas, às particularidades do adversário. De modo análogo, análises das situações ofensivas devem ser realizadas a partir de comportamentos de ataque, e também, justificadas nos comportamentos defensivos do adversário. No estudo de Travassos e colaboradores (2012), dados referentes à relação de fases entre as duas equipes indicam que a equipe nos momentos defensivos tenta desenvolver e manter padrões de coordenação espaço-temporal com as situações ofensivas e com a bola, e também considerando as informações cinemáticas com respeito à localização do gol.

O jogo de Futsal deve ser interpretado de forma sistêmica, uma vez que as equipes envolvidas em uma partida compõem dois sistemas de constante interação e movimento, a oposição configura-se como primordial para a alternância das dinâmicas táticas do jogo (GRÉHAIGNE; GODBOUT, 2014). Compreender essas relações entre o ataque e a defesa passa pela verificação dos comportamentos e intenções dos jogadores - individual e coletivamente. No estudo de Vilar e colaboradores (2013), foi constatado que as interceptações de bola tiveram relação com um menor espaço entre o defensor e o local de interceptação da bola, e, também, menor tempo para a ação. Esses dados evidenciam a relevância de compreender e desenvolver as ações, considerando as relações de cooperação e oposição (SANTANA, 2004). 
Na notícia de 1991, pode-se identificar o olhar preocupado do treinador na construção de um sistema defensivo com base em características ofensivas dos adversários. Nesse caso, o jornal A Razão também se utiliza de uma fonte primária para compor a notícia, mas reproduz a perspectiva apresentada por ela sem fazer ponderação alguma sobre possíveis equívocos da leitura estratégica do jogo. A notícia publicada em 1996, concentra-se, unicamente, em uma concepção de estratégia pautada pelo sistema adversário. Nesse sentido, além dos indícios de uma cobertura jornalística fragmentária, conforme identificados e citados anteriormente, destaca-se, nessa categoria analítica, o caráter omisso ${ }^{2}$ e equivocado de como a informação midiático-esportiva codificou a relação ataque-defesa no contexto do Futsal.

\section{Metodologia de Treino e Desenvolvimento dos jogadores}

Os treinamentos são, na maioria das ocasiões, direcionados à preparação das equipes com vistas aos jogos competitivos, fato que costuma limitar o acesso e participação da imprensa nesses ambientes. Dessa forma, as notícias correm o risco de desconsiderar a atuação no jogo a partir do treinamento, bem como evidenciam um panorama superficial sobre a condução do treinamento e desenvolvimento dos jogadores. Na Figura 5, a matéria de 1992 ressalta a escolha do treinador pelos treinos técnicos, táticos, mesclados à criatividade, porém não aponta pistas sobre como são desenvolvidos esses treinamentos. Na matéria de 1999, é evidenciado sobre as propostas que os jogadores receberam de equipes expressivas no cenário do Futsal, todavia, não se comenta sobre os contextos que auxiliaram o desenvolvimento desses jogadores.

Figura 5 - Notícias sobre a metodologia de treino e desenvolvimento dos jogadores.

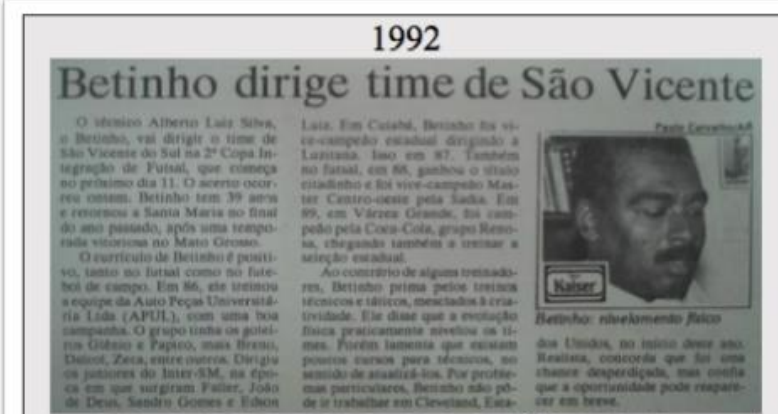

BETINHO DIRIGE TIME DE SÃO VICENTE

"Ao contrário de alguns treinadores, Betinho prima pelos treinos técnicos e táticos, mesclados a criatividade. Ele disse que a evolução física praticamente nivelou os times. Porém lamenta que existam poucos cursos para técnicos, no sentido de atualizá-los. Por problemas particulares, Betinho não pode ir trabalhar em Cleveland, Estados Unidos, no início desse ano".

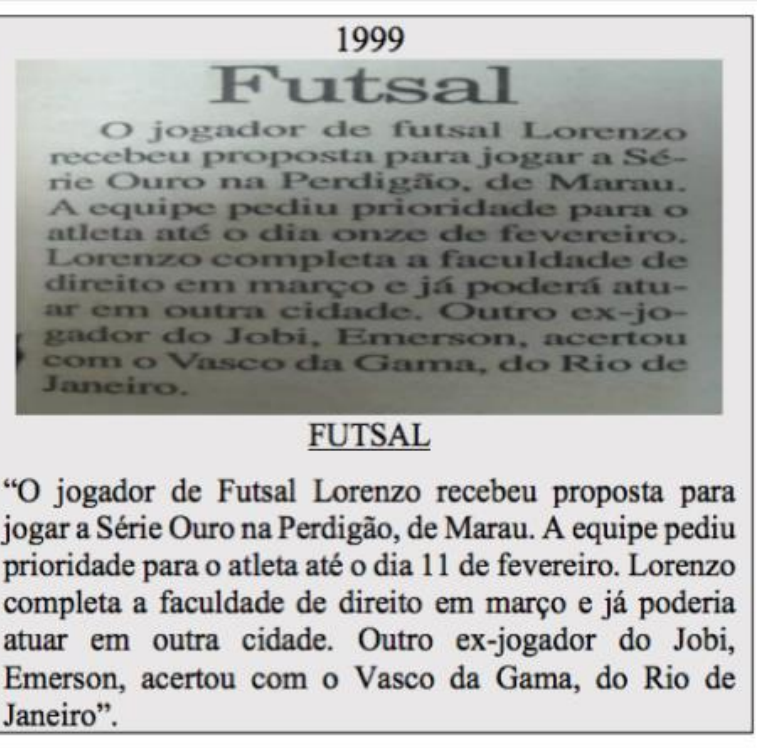

Janeiro".

\footnotetext{
${ }^{2}$ As exclusões de informações na construção das notícias também se constituem como parte a ser analisada em produtos jornalísticos, pois, segundo Rothberg (2010, p. 63), elas são "[...] as informações que deveriam estar presentes a fim de atender os critérios de pluralidade e equilíbrio em enquadramentos temáticos, completos o suficiente para um entendimento mais amplo do assunto em questão".
} 
O treinamento dos aspectos técnicos carece de contextualização à dimensão tática, fomentando a emergência de ações potencialmente importantes à resolução dos problemas de jogo e estimulando a exploração de soluções e criatividade dos jogadores (BETTEGA et al., 2015). Além das atividades de treinamento configurarem cenários oportunos para a tomada de decisão dos jogadores, outros aspectos devem ser analisados nos contextos de participação. No estudo de Vaughan e colaboradores (2019), os pesquisadores ressaltam o desenvolvimento da criatividade também ligado aos aspectos socioculturais, experiências, crenças, costumes e relacionamentos estabelecidos.

As oportunidades de prática constituem as principais fontes de desenvolvimento dos jogadores. Logo, a representação tática dos ambientes é fator primordial à evolução das ações tático-técnicas dos jogadores. De acordo com Garganta (2005), uma formação eficaz no esporte depende, em grande parte, da definição e da operacionalização de conceitos e princípios intimamente relacionados ao modo de organização das ações nos diferentes cenários de jogo. Assim, a excelência no esporte desenvolve-se pelas interações dos indivíduos com ambientes específicos de desempenho: a progressão dos jogadores advém de respostas aos estímulos e oportunidades fomentados pelos contextos de aprendizagem, treinamento e competição (GARGANTA, 2013).

Nessa última categoria analítica, foi depreendida da cobertura jornalística do A Razão o reforço à tendência em não detalhar e aprofundar elementos de contextos esportivos mais amplos, por exemplo, relatar informações mais específicas quanto aos treinamentos técnico-táticos e criativos do treinador Betinho, na notícia de 1992. Como destacado pela literatura citada, processos preparativos de atletas e equipes devem ter como referência a complexidade do próprio jogo e situações problemas inerentes a ele. Assim, a forma como a mídia esportiva analisada compôs a notícia pouco informa sobre o modus operandi dos procedimentos de treinamento, de modo que esclarecesse ao leitor os como e porquês inferidos nas rotinas de treinamentos e organização complexa dos elementos técnico-táticos. Da mesma forma, a notícia de 1999 não se atém às informações sobre características do percurso formativo dos atletas locais, que lograram trajetória no primeiro escalão do Futsal nacional, não contribuindo, portanto, para a manutenção de uma cultura de formação de jogadores de Futsal e, tampouco, ao desenvolvimento de uma cultura de busca por formação esportiva por parte de jovens atletas daquela localidade.

\section{Considerações Finais}

A tática representa um conjunto de relações que se estabelecem no jogo, ganhando contornos acíclicos, aleatórios, imprevisíveis e emocionantes, sendo fonte constante e significativa nas diferentes 
plataformas midiáticas e trazendo desdobramentos a partir de questões preestabelecidas, circunstanciais e posteriores. Os condicionantes a priori advém das mudanças de regras da modalidade, das estratégias das equipes, da metodologia de treino, do conhecimento dos jogadores, das alterações de jogadores. Circunstancialmente, das relações entre o individual e o coletivo, da interação entre o ataque e a defesa, da comunicação entre os jogadores (através de triangulações) e, posteriormente, a dimensão tática condiciona o desenvolvimento de jogo dos jogadores em um determinado período de tempo.

Compreender a dinâmica do jogo não limita-se à descrição e análise superficial das matérias jornalísticas, mas passa pela compreensão do aspecto tático, suas relações e influências. Assim, ressalta-se a importância dada pelo jornalismo impresso na divulgação da modalidade e, especificamente, do aspecto tático, reiterando que a compressão do jogo passa por uma análise mais complexa e aprofundada.

Os achados da pesquisa demonstram, em síntese, que, no período histórico analisado, a mídia local em questão exerceu o seu papel educativo de mediação da cultura esportiva, de modo a fragmentar e empobrecer a possibilidade de compreensão ampliada da complexidade do Futsal. Ao versar sobre as modificações nas regras; o papel do goleiro no jogo; a relação entre o individual e o coletivo; as estratégias na relação entre ataque e defesa; e sobre metodologias de treino e desenvolvimento dos jogadores, o jornal santa-mariense veiculou conteúdos informativos preenchidos por cisões entre as dimensões da estratégia, da tática e da técnica, o que fracionou o entendimento de composição completa do jogo esportivo coletivo.

Os dados reforçam a tendência à superficialidade do discurso midiático-esportivo, especialmente constatada em estudos sobre a mídia esportiva brasileira na década de 1990. Eles também revelam, a depender do enquadramento noticioso empreendido, que a prática jornalística tem potencial para informar, educar e formar consumidores e jogadores de esportes coletivos com concepções individualistas, seccionadas, descontextualizadas e restritas no que tange a prática de uma modalidade esportiva eminentemente caracterizada pela complexidade e instabilidade da cooperação e da oposição. Por exemplo, assim como foi identificado no jornal A Razão, o goleiro pode ser compreendido, equivocadamente, como uma peça individual da equipe de Futsal, ou, diferentemente do que foi visto, como parte de um sistema defensivo amplo e coletivo.

Especificamente sobre a mídia analisada no presente estudo, ressalta-se a importância de levar em consideração que ela não se trata de um periódico especializado em esporte ou na modalidade Futsal. Nesse sentido, ainda que possamos relativizar as análises críticas tecidas, com vistas à necessidade de uma cobertura jornalística aprofundada sobre o tema, entende-se ser o papel social do jornalismo checar e contextualizar, do modo mais completo possível, todo e qualquer tipo de informação veiculada, seja sobre política, economia ou esporte. 
Por conta da característica e do tipo de estudo desenvolvido neste trabalho, não é possível afirmar se as limitações do conteúdo jornalístico esportivo veiculado e analisado devem-se a limitações das condições e das rotinas de trabalho dos profissionais de jornalismo do jornal A Razão na época. Para obter tais informações, e não cometer juízos indevidos de avaliação da cobertura noticiosa do esporte, são necessárias investigações sobre e nos bastidores destes processos de produção de notícias, ou seja, nas redações esportivas. Esse, portanto, é um limite da pesquisa em tela e se configura, assim, como lacuna para estudos futuros sobre o tema.

\section{Referências}

AMARAL, Rui; GARGANTA, Júlio. A modelação do jogo em Futsal. Análise sequencial do 1x1 no processo ofensivo. Revista Portuguesa de Ciências do Desporto, v. 5, n. 3, p. 298-310, 2005.

ANDRADE JUNIOR, José Roulien. O Jogo de futsal: técnico e tático na teoria e na prática. Curitiba: Expoente, 1999.

BAYER, Claude. O ensino dos desportos colectivos. Lisboa: Dinalivro, 1994.

BETTEGA, Otávio Baggiotto et al. Pedagogia do Esporte: o jogo como balizador na iniciação ao futsal. Pensar a Prática, v. 18, n. 2, p. 487-501, 2015.

BETTI, Mauro. Esporte na mídia ou esporte da mídia? Motrivivência, n. 17, p. 1-3, 2001.

BUENO, Murilo et al. How do futsal players of diferente categories play during official matches? A tactical approach to players' organization on the court from positional data. Plos One, v. 13, n. 6 , e0199619, 2018.

CAETANO, Rafael et al. Análise do tempo de posse de bola e a sua influência no resultado dos jogos do campeonato mundial de futsal. Revista Brasileira de Futsal e Futebol, v. 7, n. 23, p.16-20, 2015.

DUARTE, Ricardo. Análise da utilização da posse de bola durante o processo ofensivo no futsal.

Motricidade, v. 4, n. 2, p. 77-83, 2008.

GALATTI, Larissa Rafaela et al. O ensino dos jogos esportivos coletivos: avanços metodológicos dos aspectos estratégico-tático-técnicos. Pensar à Prática, v. 20, n. 3, p. 639-654, 2017.

GANEF, Edson et al. Influência do goleiro-linha no resultado do jogo de Futsal. Revista Brasileira de Futsal e Futebol, v. 1, n.3, p.186-192, 2009.

GARGANTA, Júlio. A análise da performance nos jogos desportivos. Revisão acerca da análise do jogo. Revista Portuguesa de Ciências do Desporto, v. 1, n. 1, p. 57-64, 2001.

GARGANTA, Júlio. Dos constrangimentos da acção à liberdade de (inter)acção, para um futebol com pés... e cabeça. In: ARAÚJO, Duarte. (Ed.). O contexto da decisão. A acção táctica no desporto. Lisboa: Visão e Contextos, p. 179-190, 2005. 
GARGANTA, Júlio. A propósito do desenvolvimento, da identificação, e da atualização do talento para treinar e jogar futebol. In: NASCIMENTO, Juarez Vieira; RAMOS, Valmor; TAVARES, Fernando. (Org.). Jogos desportivos: formação e investigação. Florianópolis: Tribo da Ilha, 2013.

GRÉHAIGNE, Jean-Francis; GODBOUT, Paul. Dynamic systems theory and team sport coaching. Quest, v. 66, n. 1, p. 96-116, 2014.

HELAL, Ronaldo. Mídia, a construção da derrota e o mito do herói. Motus corporis, v. 5, n. 2, p. $141-$ $155,1998$.

HENRIKSEN, Kristoffer; STAMBULOVA, Natalia; ROESSLER, Kirsten. Holistic approach to athletic talent development enviroments: a successful sailing milieu. Psychology of Sport and Exercise, v. 11, n. 3, p. 212-222, 2010.

KUMAHARA, Robson et al. Análise qualitativa das ações e do sistema de jogo de equipes profissionais de futsal. Coleção Pesquisa em Educação Física, v. 8, n. 1, 2009.

MARQUES, Heitor et al. Metodologia da pesquisa e do trabalho científico. 5. ed. Campo Grande: UCDB, 2017.

MARQUES, Renato; MARCHI JÚNIOR, Wanderley. A cobertura midiática sobre o futsal masculino no brasil: perspectiva dos atletas da seleção brasileira principal. Movimento, v. 25, e25018, 2019.

PIRES, Giovani De Lorenzi. A Educação Física e o discurso midiático: abordagem críticoemancipatória. Ijuí: Unijuí, 2002.

PIRES, Giovani De Lorenzi; LAZZAROTTI FILHO, Ari; LISBÔA, Mariana Mendonça. Educação Física, mídia e tecnologias - Incursões, pesquisa e perspectivas. Kinesis, v. 30, n. 1, p. 55-79, 2012.

ROTHBERG, Danielo. O conceito de enquadramento e sua contribuição à crítica de mídia. In: CHRISTOFOLETTI, Rogério. (Ed.). Vitrine e Vidraça: crítica da mídia e qualidade no jornalismo. Florianópolis: LabCom Books, 2010. p. 53-68.

SAAD, Michel et al. Impacto das metodologias empregadas pelos treinadores no desenvolvimento técnico tático individual dos jogadores de futsal das categorias sub-13 e sub-15. Revista Brasileira Ciência e Movimento, v. 22, n. 2, p. 96-105, 2014.

SALLES, José; MATTOS, Edmundo. Futsal: alterações de regras e suas influências no processo de treino. Revista Mineira de Educação Física, v. 4, n. 1, p. 16-24, 1996.

SANTANA, Wilton. Futsal: apontamentos pedagógicos na iniciação e na especialização. Campinas: Autores Associados, 2004.

SANTOS, Doriana; MEDEIROS, Ana Gabriela. O discurso midiático e as representações sociais do esporte: o atleta como modelo de comportamento. Pensar a prática, v. 12, n. 3, p. 1-11, 2009. 
SCHMITZ FILHO, Antonio Guilherme. A CPI do futebol: agendamento e processualidades sistêmicas. (Tese de Doutorado). Curso de Ciências da Comunicação, Universidade do Vale do Rio dos Sinos (UNISINOS), São Leopoldo/RS, 2005.

SOUZA, Carlos Eduardo et al. Goleiro-linha e linha-goleiro: diferentes usos estratégico-táticos do goleiro na liga nacional de futsal de 2016. Revista Brasileira de Futsal e Futebol, v. 10, n. 41, p. 655-662, 2018.

SPÀ, Miquel. Comunicación y deporte en la era digital: sinergias, contradicciones y responsabilidades educativas. Contratexto, v. 12, p. 73-92, 1999.

TRAVASSOS, Bruno et al. Interpersonal coordination and ball dynamics in futsal (indoor football). Human Movement Science, v. 30, n. 6, p. 1245-1259, 2011.

TRAVASSOS, Bruno et al. Spatiotemporal coordination behaviors in futsal (indoor football) are guided by informational game constraints. Human Movement Science, v. 31, n. 4, p. 932-945, 2012.

VAUGHAN, James et al. Developing creativity to enhance human potential in sport: a wicked transdisciplinary challenge. Frontiers, v. 10, n. 2090, p. 1-16, 2019.

VICENTE-VILAS, Pedro; LAGO-PEÑAS, Carlos. The goalkeeper influence on ball possession effectiveness in futsal. Journal of Human Kinetics, v. 51, n. 2, p. 217-224, 2016.

VILAR, Luís et al. Spatial-temporal constraints on decision-making during shooting performance in the team sport of futsal. Journal of Sports Sciences, v. 31, n. 8, p. 840-846, 2013.

VOSER, Rogério. Futsal: princípios técnicos e táticos. Canoas: Ulbra, 2003.

\section{Como citar este artigo}

BETTEGA, O. B.; MARQUES FILHO, C. V.; SILVA, L. P. N.; SANTOS, S. M. A dimensão tática do Futsal na cobertura jornalística de uma mídia impressa de Santa Maria-RS (1990 - 1999). Revista Kinesis, Santa Maria, v. 39, p.01-15, 2021.

* O presente trabalho não contou com apoio financeiro de nenhuma natureza para sua realização. 